\title{
PRÁTICAS SOCIÁTRICAS ON-LINE: NOVOS ESTUDOS E EXPERIÊNCIAS
}

\author{
ONLINE SOCIATRIC PRACTICES: NEW STUDIES AND EXPERIENCES \\ PRÁCTICAS SOCIÁTRICAS ON-LINE: NUEVOS ESTUDIOS Y EXPERIENCIAS

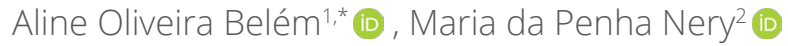

A Revista Brasileira de Psicodrama (RBP), nos últimos dois anos, tem publicado diversos artigos sobre Psicodrama on-line, que contribuem para nossas reflexões e práticas profissionais. Esse número da RBP busca complementar esse repertório, e tem como foco os estudos de psicodramatistas sobre suas experiências e estratégias na prática sociátrica em ambientes virtuais.

As autoras e os autores deste número apontam algumas vicissitudes dessa prática e apresentam as consequências dela na vida dos participantes. Tais experiências são o resultado de passarmos, no Brasil e no mundo, pela pandemia por Covid-19 e, com isso, de necessitarmos imergir no atendimento on-line, utilizando os diversos métodos de ação, dentre eles: psicodrama bipessoal, psicoterapia psicodramática de grupo, psicodrama com crianças, psicodrama pedagógico, sociodramas, sociopsicodramas, teatros espontâneos, e em cursos de formação e de aperfeiçoamentos na área.

O contexto histórico da pandemia proporciona intensos sofrimentos pessoais e coletivos, e ocorre num momento em que a virtualidade se acirra, estabelecendo as relações por meio das redes sociais, da internet, das tecnologias digitais e dos ambientes virtuais. Esse contexto traz uma angustiante transição entre o novo e o antigo, por exemplo, na construção de nossas subjetividades, nos processos de trabalho, nas experiências de lazer, nas relações humanas e na vida social.

Segundo Bauman (2001), vivemos a modernidade líquida, em que as pessoas criam frágeis interações, com baixa tolerância às divergências e às diferenças. As relações líquidas, associadas às relações virtuais, têm alto grau de conexão e de desconexão, reconstruindo a subjetividade, com a cultura do consumo e com a massificação das tecnologias. Os laços humanos e afetivos são fugazes, surgem e se desfazem em velocidade, com resposta às tarefas em rápidas mudanças. Para o autor, nas interações virtuais, as pessoas constroem um imaginário sobre a realidade, ou uma estetização da realidade, para suprir ausências internas.

Neste contexto social, os psicodramatistas assumem um protagonismo de realizar psicoterapias e socioterapias por meio do ambiente virtual, seguindo a criatividade de Moreno de trabalhar com as tecnologias da sua época (Moreno, 1984). Nos atendimentos virtuais, os psicodramatistas acolhem as dores dos participantes das sessões, dão suportes aos sofrimentos, ajudam na manifestação da espontaneidade-criatividade e tratam os sintomas de pessoas e grupos em uma pandemia na sociedade líquida e digital.

Quanto ao atendimento on-line, Fleury (2020) apresenta alguns argumentos éticos favoráveis ao trabalho da telepsicologia ou telepsicodrama, a exemplo do fato de que o atendimento remoto amplia possibilidades ao considerar o alcance a regiões mais afastadas (a exemplo de zonas rurais), a pessoas que são estrangeiras nos países onde residem, além das vantagens econômicas. Porém, desde março de 2020, a motivação principal para o atendimento remoto, em larga escala, tem sido a pandemia por Covid-19.

No ambiente digital, os atendimentos podem ser realizados de forma síncrona, quando os participantes estão conectados em tempo real, por meio de telechamadas e videochamadas; ou de forma assíncrona, quando a interação entre as pessoas interlocutoras se dá em horários diferentes, minimizando muitas vezes problemas de conexão à internet (Meyer \& Prado, 2006). Podem-se usar e-mails, troca de mensagens por aplicativos de conversa, como WhatsApp e Telegram, ou troca de áudios gravados.

1.PROFINT - Profissionais Integrados - Aracaju (SE), Brasil.

2.Associação Brasiliense de Psicodrama - Brasília (DF), Brasil.

*Autora correspondente: alineobelem@hotmail.com 
Na prática sociátrica on-line, seguem-se as determinações éticas do Conselho Federal de Psicologia (Resolução CFP n. 11,2018). Os profissionais realizam os ajustes técnicos e dos dispositivos eletrônicos, para o aperfeiçoamento do manejo no ambiente virtual, observam os fatores logísticos que garantam a confidencialidade, bem como os fatores emocionais, que favoreçam a continência terapêutica, com a segurança e a confiança necessárias ao trabalho.

Podemos afirmar que, inicialmente, nos debruçávamos mais sobre as limitações do que sobre as potencialidades do atendimento on-line. Weinberg (2021), ao discorrer a respeito da psicoterapia de grupo on-line, afirma que evidentemente não é possível compensar todas as limitações do atendimento remoto (a exemplo da falta de contato corporal), mas afirma também que este apresenta mais vantagens que desvantagens, em especial durante a pandemia. Além disso, o autor nos mostra que é possível haver o desenvolvimento de uma aliança terapêutica forte no atendimento on-line, ainda que ela possa levar um pouco mais de tempo para se estabelecer, se comparada ao seu desenvolvimento no atendimento presencial.

A princípio, quando se deflagrou a necessidade de isolamento social para todo o mundo, o pensamento de muitos psicodramatistas foi, como mencionado em Kornienko (2020, p. 4), “Eu não sei fazer nada agora”. Porém, no atual momento, observa-se que houve um acúmulo de ricas experiências no atendimento virtual a ponto de se tornar possível afirmar que, sim, avançamos e amadurecemos bastante enquanto psicodramatistas.

Kornienko (2020), no seu trabalho com grupos on-line, apresentou contribuições, tais como: o aperfeiçoamento do manejo com os equipamentos; a necessidade de uma expressão mais firme e explícita por parte do diretor; a oferta de apoio para que os membros de um grupo reajam uns aos outros, inclusive com a expressão física das emoções. Essas conclusões se relacionam com o conceito de aquecimento e de sua manutenção, agora no ambiente virtual.

Ramalho (2020), ao discorrer sobre o Psicodrama a dois on-line, aponta alguns exemplos, dentre eles: solicitação de posicionamento da câmera de ambos (terapeuta e cliente) para realização de aquecimento corporal; o uso de objetos intermediários para representar personagens ou elementos da cena; expressão através das mãos; solicitação de desenhos das cenas feitos pelo cliente. A autora apresenta estratégias de ação para o atendimento on-line: a dramatização internalizada e a entrevista no papel, e a utilização das técnicas de ação: inversão de papéis, duplo, espelho e solilóquio.

Armañanzas Ros (2020) organizou um conjunto de recursos e exercícios para o Psicodrama de grupo on-line, propondo criativos ajustes, como iniciar a sessão dizendo “ação!" e solicitando que os membros do grupo dublem a si mesmos (falando o que pensam como se fossem dubladores). O autor usa a técnica do solilóquio já no aquecimento inespecífico.

Recentemente, Echenique (2021) organizou o livro Psicodrama virtual. Nesse livro, um grupo de psicodramatistas relata suas experiências com atendimento virtual ou remoto. Os profissionais nos mostram o caminho da espontaneidade para o desenvolvimento da criatividade, com o compartilhar dos afetos e dos conhecimentos.

Esse suplemento apresenta estudos de experiências que contemplam o máximo de frentes de atuação possível com métodos terapêuticos de ação on-line. Há o trabalho de Psicodrama com crianças, com grupos psicoterapêuticos, com grupos com fins pedagógicos. Há vivência sociodramática de ato único, ou múltiplas vivências.

Tentou-se, neste número, contribuir teórica e tecnicamente para nossas atuações profissionais, porém, observa-se a necessidade de estudos aprofundados. Precisa-se conhecer e criar mais sobre, por exemplo, a virtualidade, a realidade virtual e suas conexões com o Psicodrama; especificidades do atendimento on-line com métodos de ação; diferenças entre atendimento virtual e presencial e a eficácia dos métodos on-line.

\section{REFERÊNCIAS}

Armañanzas Ros, G. (2020). Recursos e Ejercicios de Terapia de Grupo y Psicodrama Online. Grupos Escuela de Psicodrama.

Bauman, Z. (2001). Modernidade líquida. Zahar.

Echenique, M. (Org.). (2021). Psicodrama virtual: Explorando a toca do coelho. Araucária.

Fleury. H. J. (2020). Psicodrama e as especificidades da psicoterapia on-line. Revista Brasileira de Psicodrama, São Paulo, 28(1), 1-4. https://doi.org/10.15329/2318-0498.20203

Kornienko, P. (2020). Aspectos especificos sobre la conducción de grupos terapéuticos en un entorno online. https:// psychotherapy-lab.ru/wiki/pg14/es 
Meyer, B. S. e Prado, O. Z. (2006). Avaliação da relação terapêutica na terapia assíncrona via internet. Psicologia em Estudo, Maringá, 11(2), 247-257. https://doi.org/10.1590/S1413-73722006000200003

Moreno, J. L. (1984). Psicodrama (3a ed., A. Cabral, Trad.). Cultrix. (Obra original publicada em 1975).

Ramalho, C. M. R. (2020). Psicodrama a dois on-line: Desafios e especificidades. In J. P. C. de Santana et al. (Orgs.), Interfaces dos atendimentos psicológicos on-line.

Resolução CFP n. 11 (2018). Regulamenta a prestação de serviços psicológicos realizados por meios de tecnologias da informação e da comunicação e revoga a Resolução CFP n. 11/2012. Conselho Federal de Psicologia. https:// atosoficiais.com.br/lei/orientacao-psicologica-pela-internet-cfp?origin=instituicao

Weinberg, H. (2121). Obstacles, Challenges, and Benefits of Online Group Psychotherapy. American Journal of Psychotherapy in Advance. https://doi.org/10.1176/appi.psychotherapy.20200034 